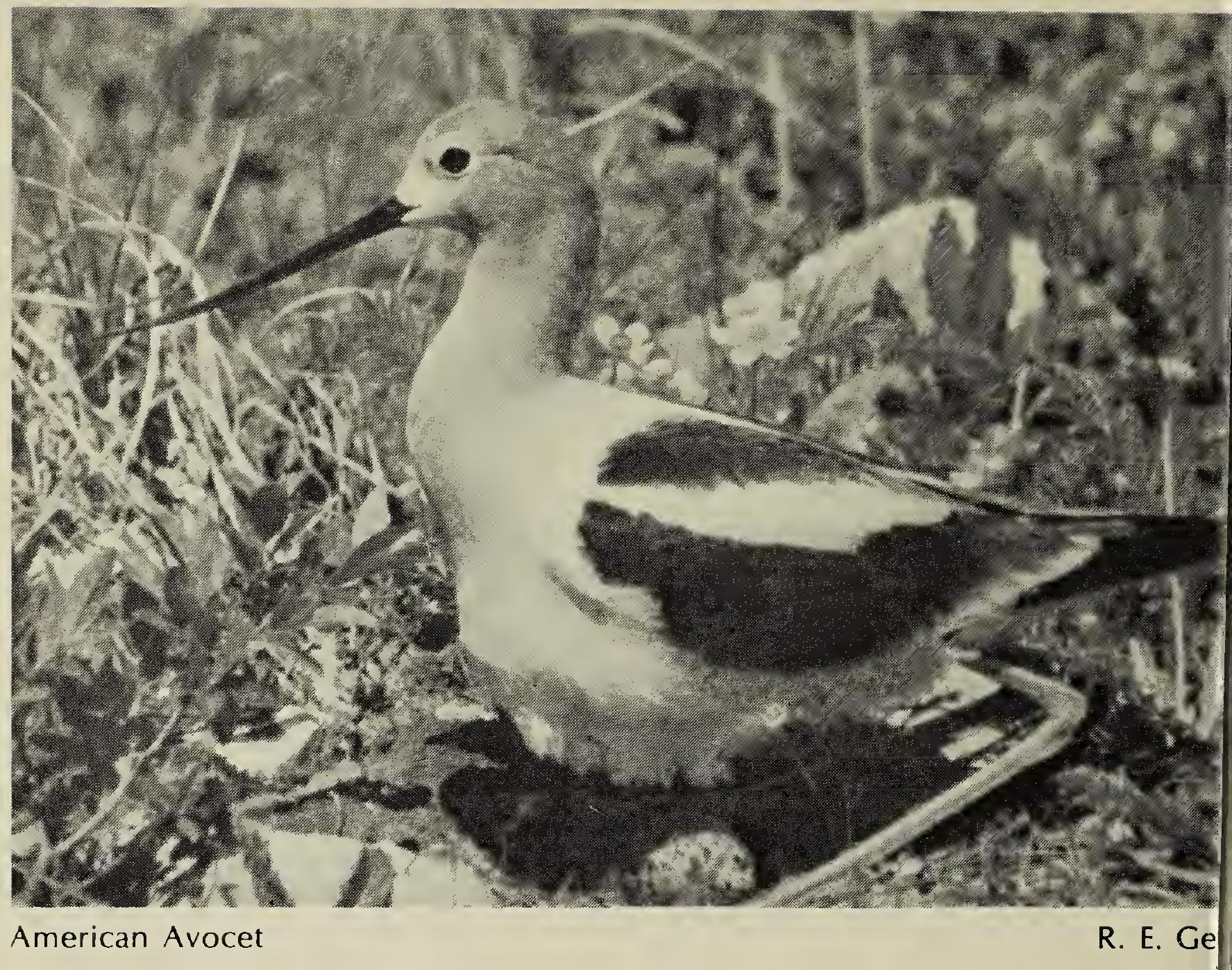

\title{
AN UNUSUAL AMERICAN AVOCET NEST
}

NORBERT G. KONDLA, Parks Planning and Design Branch, Alberta Recrea Parks and Wildlife, 9912 - 106 Street, Edmonton, Alberta

On June 1, 1972, W. W. Smith and I explored a small island in Goosequill Lake, Alberta (30 miles SE of Red Deer). One end of this island consisted of a low, rocky spit with scant vegetation and white, salt-saturated soil. Here we found two American Avocet nests, one with seven eggs and one with eight eggs. Both clutches were comprised of two distinct types of eggs. The seven-egg clutch had three eggs different from the other four while the eight-egg clutch had four eggs different from the other four.

When we visited the island again on June 15, the nest and egg tally was substantially different. The nest of seven eggs was the same. The e egg nest was radically altered. location I discovered two nests four eggs each (Fig. 1). Each "clu consisted of two dark toned egg two light toned eggs. Another had only a single egg. Two nests had four eggs, one with a clut similar eggs but the other had eggs different from the rema egg. A sixth nest had five eggs, of one type and two of anothei

These observations indicate two Avocets each laid their no complement of four eggs in a mon nest. ${ }^{2} 2$ A dispute then res and the eggs were divided bet the two birds. It is unknown i 


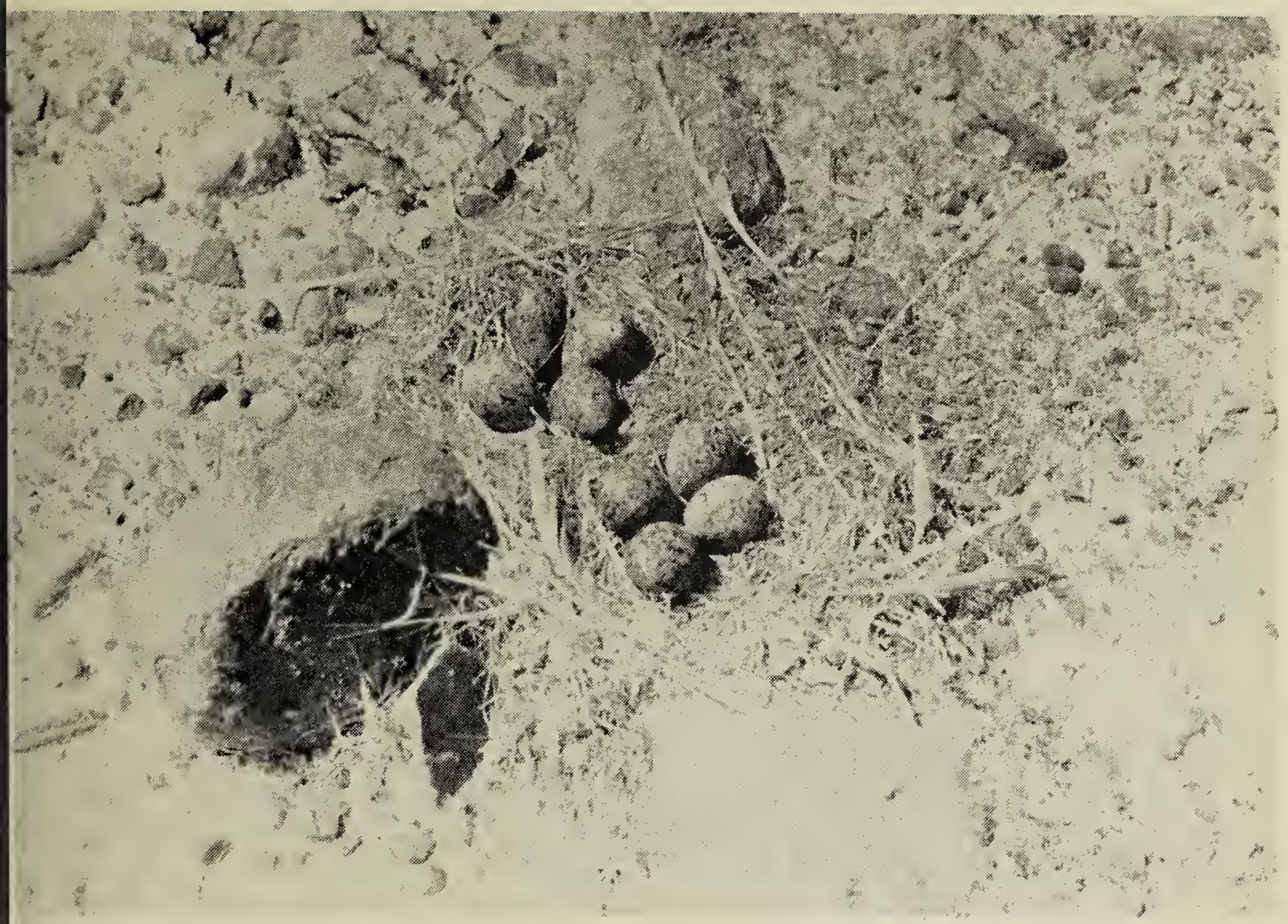

Norbert G. Kondla Split clutch of American Avocet. Goosequill Lake, Alberta, June 15, 1972.

rather than two birds were ined. The outcome of this nest is known.

e observations also suggest a surng lack of nest fidelity on the part ying females. Standard references to four eggs as being the normal ch but it is not evident that all four in an avocet nest are laid by only bird. Gibson, in calculating the ch size of American Avocets, exed nests with six or more eggs his data because he found two nct types of eggs in such nests. ${ }^{2}$ observations reported above plus $y$ other avocet nests seen by elf indicate that even four and egg nests may be the product of birds.

ch an unusual nest is but an exhe example of highly interesting aviour on the part of colonial ets. Gibson's work showed that sexes incubate and defend tories, although incubating birds not leave the nest to defend the territory from other avocets. ${ }^{2}$ The hanism by which territory is ted in the formation of com- posite nests is not known. Equally intriguing is the prospect that unpaired females may be involved in these nests. Gibson observed opportunistic copulations by birds outside the pair bond and eggs resulting from these could well be deposited in existing nests. Gibson also found that eightegg clutches had a lower hatching success than smaller clutches. He attributed this to the inability of birds to adequately cover such clutches with the brood patch. This lowered success could also be at least partially explained by the four possible "parents" of such a nest indulging in extensive squabbling over incubation duties. Prairie naturalists have the opportunity to make highly interesting behavioural observations at local colonies.

'BENT, A. C. 1927. Life histories of North American shore birds (Part 1). Smithsonian Inst. U.S. Nat. Mus. Bull. 142 (Dover edition, 1962)

${ }^{2}$ GIBSON, F. 1971. The breeding biology of the American Avocet (Recurvirostra americana) in central Oregon. Condor $73: 444-454$ 